\title{
Fibroblastic Variant of Osteosarcoma: A Challenge in Diagnosis \& Management
}

\author{
Dinkar Desai ${ }^{1, *}$, Siddharth Pandith ${ }^{1}$, Prabhakar A Jeergal ${ }^{1}$, Arathi $^{1}$ and Rajan Saini ${ }^{2}$ \\ ${ }^{I}$ Department of Oral and Maxillofacial Pathology, A.J. Institute of Dental Sciences, Mangalore 575004, Karnataka, \\ India \\ ${ }^{2}$ School of Dental Sciences, Universiti Sains Malaysia, Kubang Kerian 16150, Kelantan, Malaysia
}

\begin{abstract}
Osteosarcoma of the jaws is a relative rare malignant bone tumor. Like, its counterpart in the long bones, osteosarcoma affecting the head and neck region shows distinct yet diverse clinical, histologic and prognostic characteristics. Its diagnosis is a challenge to histopathologists and is especially important in early stages to improve its prognosis. In the initial phase, it may present as nondescript swelling with an indolent growth rate, only to become overtly aggressive and malignant towards the later phase of the disease. This article reports on a case of an advanced osteosarcoma of the maxilla in a 42 year old woman who came for the evaluation of a swelling. The case was submitted for surgical intervention and was followed by one recurrence till the time of reporting. This case illustrates that immunohistochemical staining of Vimentin, S-100 and CD 68 markers are useful to confirm the histologic diagnosis of osteosarcoma, along with radiographic evaluation using CT scan and 3D imaging.
\end{abstract}

Key Words: Osteosarcoma, fibroblastic, bone neoplasm, maxilla.

\section{INTRODUCTION}

Although, the incidence of osteosarcoma (OS) among malignant tumors is low, it is still the most common primary tumor of bone [1]. It belongs to a family of lesions which have considerable diversity in histologic features and grades [2]. OS arising from the jaw comprises $2.1 \%$ of all malignant oral and maxillofacial tumours [3]. OS of jaw differs from OS of the long bones in its biological behavior, presenting a lower incidence of metastasis [4] and a better prognosis with approximately $40 \% 5$-year survival rate as compared to $20 \%$ for non-jaw lesions [5].

In the initial phase of the disease, OS may present as an unremarkable slowly progressing bony swelling, only to become overtly aggressive and malignant towards the latter phase of the disease, thus imposing a challenge to accurate diagnosis [1]. Histologically, OS is classified into three subtypes: osteoblastic, chondroblastic, fibroblastic [6]. However, it may have various degrees of differentiation and produce various kinds of extracellular matrix, thus producing a histologic pattern that may vary significantly, not only from one case to another, but also from area to area within the same case. OS are believed to arise from immature boneforming cells or through neoplastic differentiation of other immature mesenchymal cells into osteoblasts. Three main factors generally are purposed to be etiologically significant in their development -irradiation, preexisting benign bone disorders and trauma [4]. OS tumorigenesis has been linked to alterations in several genes. The first association of OS

*Address correspondence to this author at the Department of Oral and Maxillofacial Pathology, A.J. Institute of Dental Sciences, Mangalore 575004, Karnataka, India; Tel: +91 9845263743; Fax: +91 08242225541; E-mail: dinkar22desai@gmail.com with an inherited predisposition was observed in patients with bilateral retinoblastoma. This association was confirmed by identification of the retinoblastoma susceptibility gene (RB1) on human chromosome 13 which showed high percentage of mutations in OS [7]. The second gene associated with OS was the p53 gene where the mutations in the p53 gene were first observed in sporadic OS [8,9].

Here, we present a rare case report of OS in a 42 year old female patient, who had a swelling in the maxillary region with varied histologic appearance mimicking proliferative reactive lesions, thus posing a challenge to pathologic diagnosis and effective surgical management of the case.

\section{CASE REPORT}

A 42 year old female patient presented with a solitary swelling in the left middle-third of the face. The swelling had been present for a month. Extraorally, the swelling measured around $2 \times 2 \mathrm{cms}$ (Fig. 1A). It was firm in consistency, tender on palpation and the overlying skin appeared stretched and shiny. There was associated lymphadenopathy. Intraorally, the swelling extended anterioposteriorly from distal aspect of 23 to distal aspect of 27 (Fig. 1B). Lateral extension revealed the obliteration of the buccal vestibule, medially up to the midpalatal area. A root stump was present in relation to upper left first premolar. Investigations like intra oral periapical radiograph showed periapical rarifying osteitis with increase in the width of periodontal ligament membrane in relation to 26 (Fig. 1C). Orthopantamograph revealed a root stump in relation to 24 and increase width of periodontal ligament membrane with loss of lamina dura in relation to 26 (Fig. 1D). Considering the findings, a provisional diagnosis of infected periapical pathology in relation to 26 was given. Patient was advised extraction of the root 


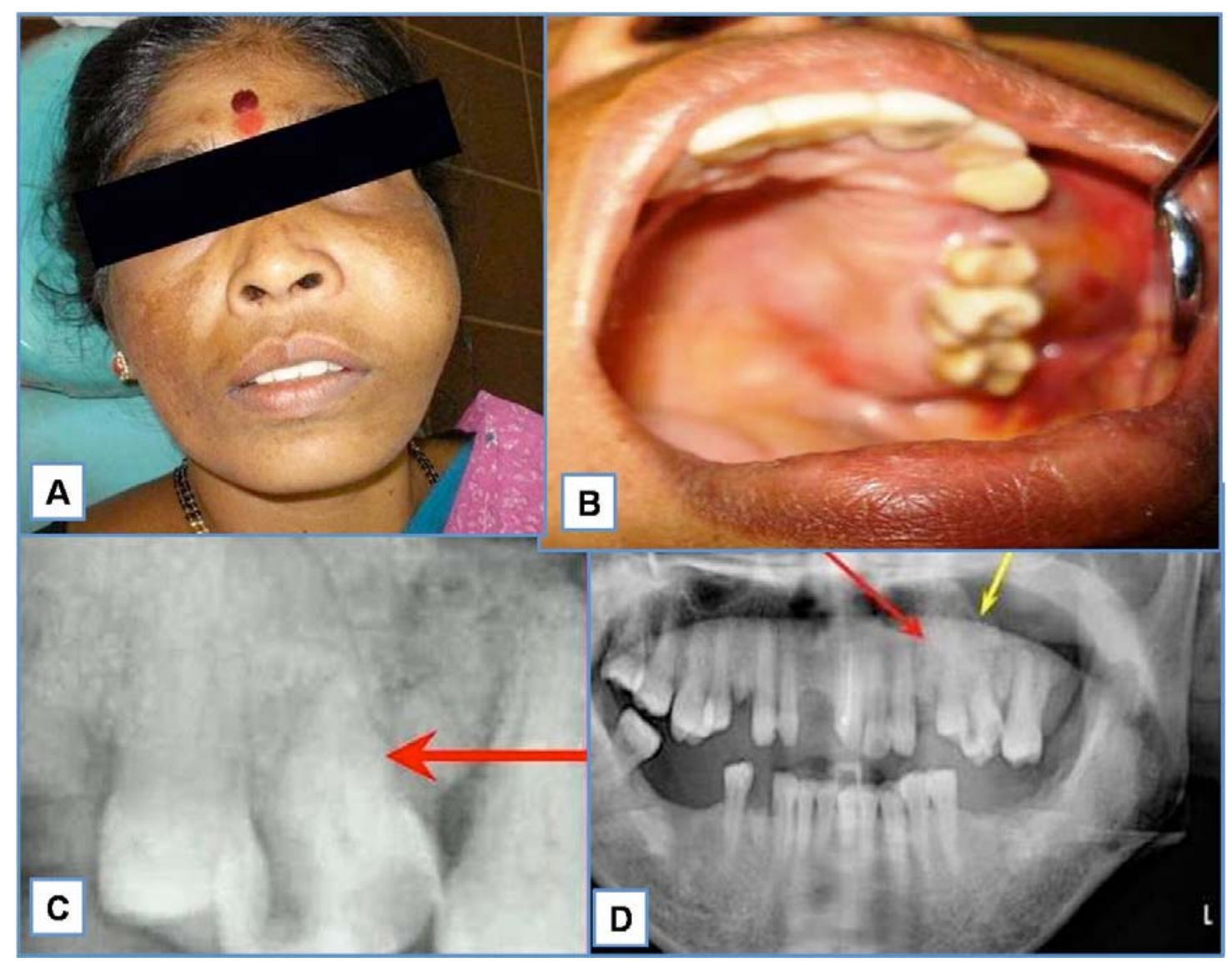

Fig. (1). A. Extra oral swelling measuring $2 \times 2 \mathrm{cms}$ in the left middle third of the face. B. Swelling extending anterioposteriorly from the distal aspect of 23 to distal aspect of 27. C. Intraoral periapical radiograph showing periapical rarifying osteitis with increase in width of periodontal ligament membrane in relation to 26. D. Orthopentamograph showing root stump in relation to 24 and increase width of periodontal ligament membrane with loss of lamina dura in relation to 26.

stump and endodontic therapy for 26. Following treatment, patient reported back to the hospital within two weeks with significant increase in the size of the swelling from $2 \times 2 \mathrm{cms}$ at the first visit to $6 \times 5 \mathrm{cms}$ (Fig. 2A). On examination, a foul smelling, reddish black mass measuring $6 \times 5 \times 6 \mathrm{cms}$, pedunculated swelling was seen arising from the extracted socket of 24 (Fig. 2B). Palpatory findings revealed the swelling to be firm in consistency, tender on palpation and slight bleeding on probing. These features suggested a provisional diagnosis of central giant cell granuloma. Additional investigations were done that included hematological investigation which revealed increase in blood glucose and ESR levels. Radiographic investigations of paranasal sinus showed haziness of the left maxillary sinus, with erosion of infra orbital, medial and lateral walls. Computed tomography revealed a large expansile lesion arising from the lateral wall of the superior alveolus of the maxilla of the left side, extending into the left maxillary sinus and eroding all the walls of the maxillary sinus (Fig. 2D). CT morphology suggested the possibility of a giant cell tumor.

An incisional biopsy was performed and histopathological findings showed a nonspecific infection suggesting an inaccurate biopsy site (Fig. 2C). A repeat biopsy was requested in relation to deeper areas. However, patient reported back within two days of incisional biopsy with a further increase in the size of the swelling with the lesion pro- truding out of the oral cavity causing inability to close the mouth (Fig. 3A). An immediate partial maxillectomy was done based on the clinical features, computed tomography findings, to avoid further encroachment of the base of the skull (Fig. 3B). The resected mass weighed about $250 \mathrm{gms}$, measuring $14 \times 8 \mathrm{cms}$ (Fig. 3C). Histopathology showed the lesion to be composed of proliferating fibroblasts along with bundles of collagen fibers. A markedly cellular lesion comprising of mature proliferating fibroblasts with infrequent mitosis and occasional atypia was seen (Fig. 4A). There was a presence of abundant inflammatory cells along with few reactionary giant cells, interspersed with a myxoid background (Fig. 4B). Storiform pattern of arrangement of fibroblasts was also seen, with the fibroblasts showing atypia in relation to size and shape. Invasion into the adjacent adipose tissue was also noted. Immunohistochemical staining was performed with vimentin markers and S-100 protein. Vimentin positivity proved the myofibroblastic nature of the spindle cell lesion (Fig. 4C). S-100 was negative, thus ruling out neural tumours (Fig. 4D). Based on the clinical picture, rate of growth of the lesion and histopathological findings, a final diagnosis of fibrosarcoma was given. Patient reported back with an uneventful healing following which functional and esthetic reconstruction was done by giving an obturator. After hemimaxillectomy, chemotherapy was administered which included Cysplatin $80 \mathrm{mg} / \mathrm{m} 2$ on day 1 along with 5 


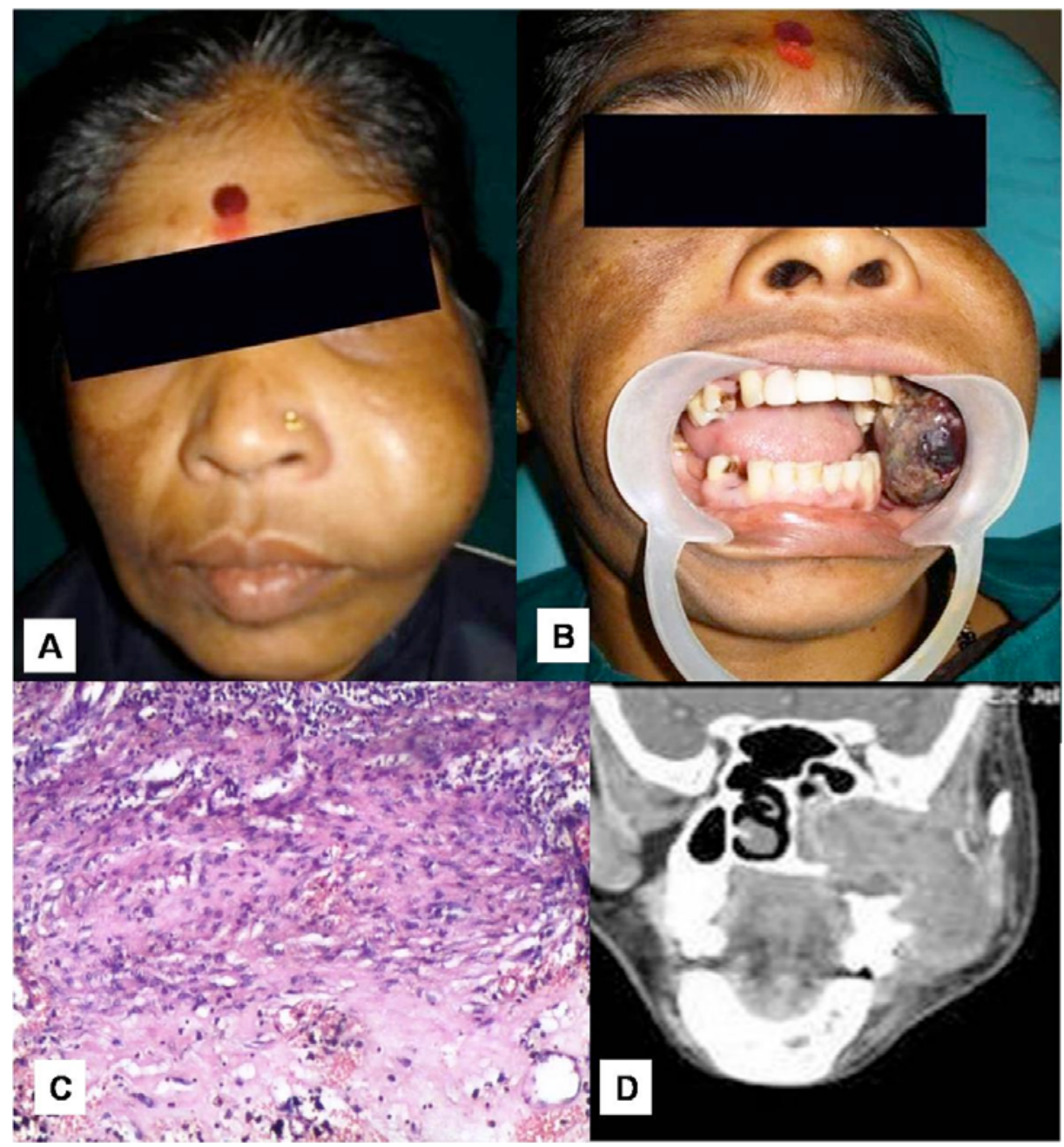

Fig. (2). A. Swelling measuring $6 \times 5 \mathrm{cms}$. B. Reddish black pedunculated mass measuring $6 \times 5 \times 6 \mathrm{cms}$ from the extracted tooth socket 24 . C. Histopathology of incisional biopsy showed a non specific infection. D. Computed tomography showing the extension of the swelling into the left maxillary sinus \& causing erosion of all the walls.

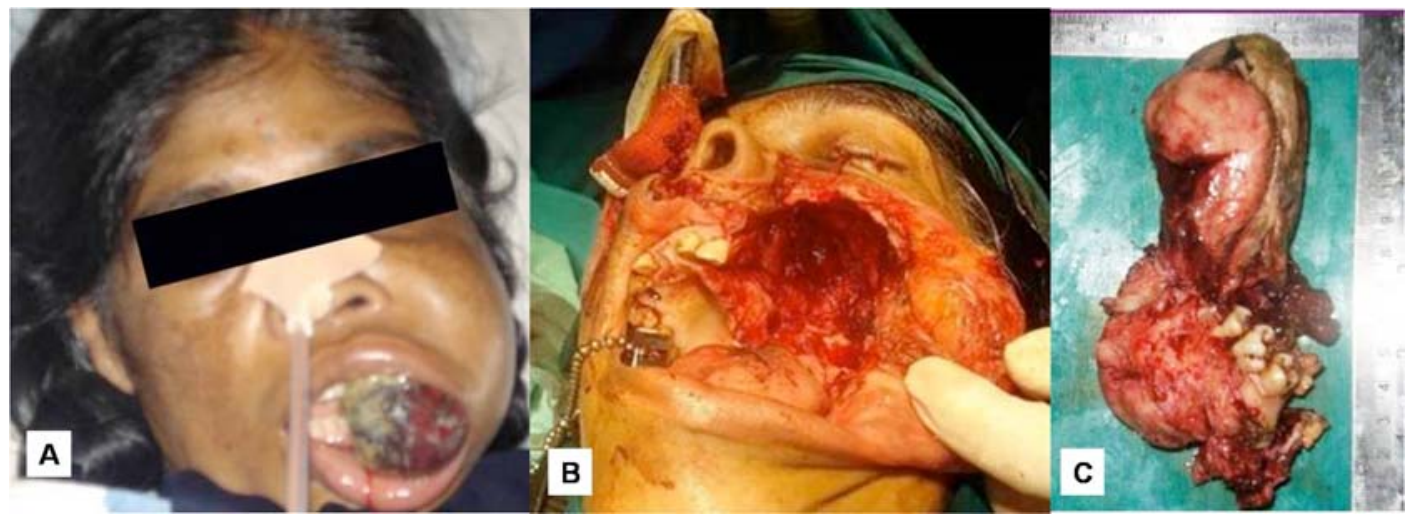

Fig. (3). A. Further increase in the size of the swelling causing inability in closing the mouth. B. Immediate partial maxillectomy being carried out. C. Complete resected mass measured $14 \times 8 \mathrm{cms}$.

Fluorouracil - 500mg/m2 which was administered on day 1 to 4. This resulted in partial response of the tumour with stoppage of bleeding. Patient also underwent a course of radiotherapy (60 Gy over 6 weeks). The decision to give radiotherapy was made taking into consideration the large size of the lesion along with a history of recurrence. After surgery, an acrylic plate obturator was placed which was to be replaced by a cast partial hollow bulb closed obturator.

There was no evidence of recurrence for six months after which patient reported back with a complaint of pain in the same region with difficulty in eating and carrying out routine oral hygiene procedures. Extra orally a diffuse solitary swel- 


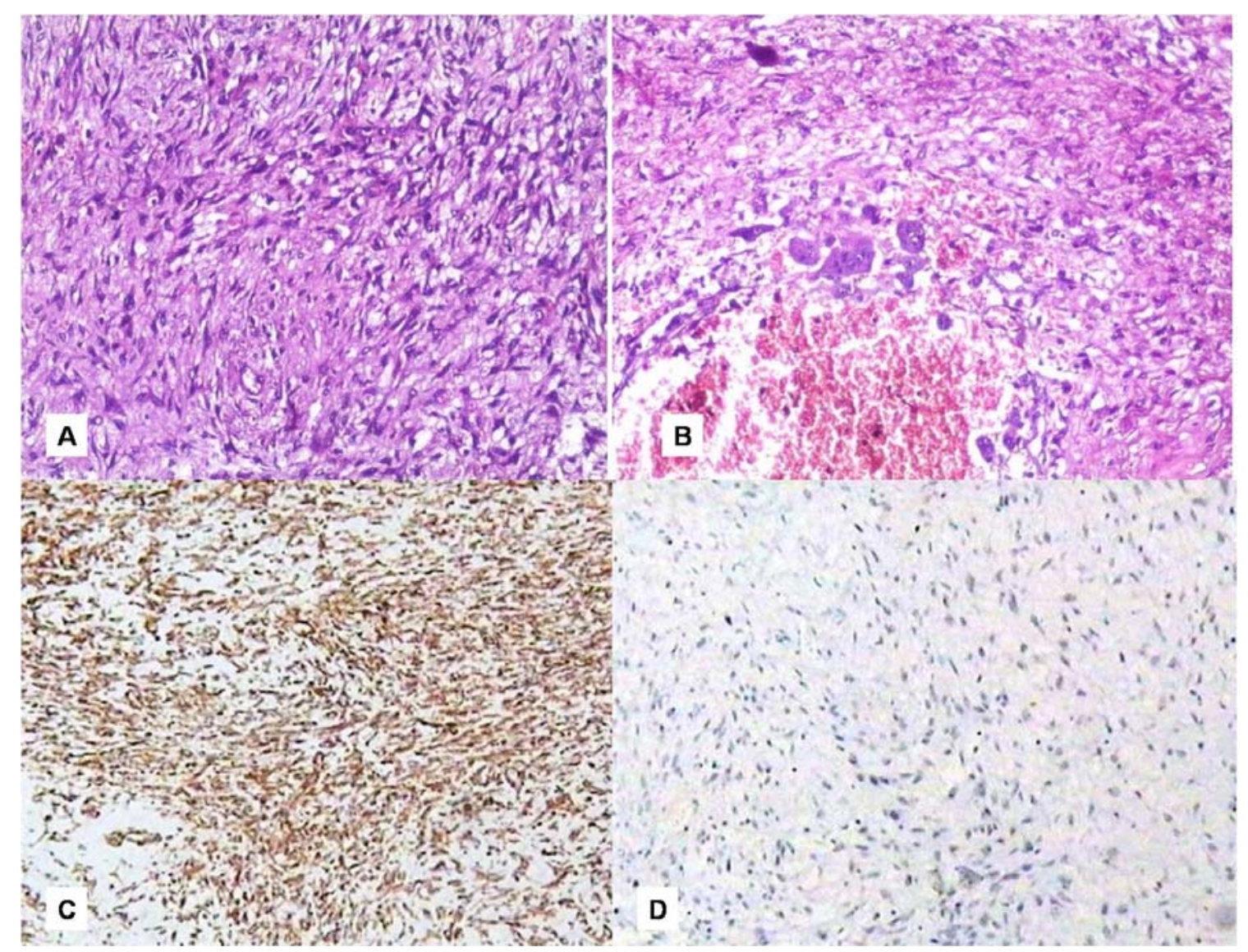

Fig. (4). A. Histopathology showed a markedly cellular lesion with proliferating fibroblasts. B. Presence of few reactionary giant cells. C. IHC showing positivity to Vimentin marker. D. Immunohistochemistry with S-100 marker being negative.

ling measuring $2 \times 2 \mathrm{cms}$ was seen in the left middle-third of the face with associated lymphadenopathy. Intra orally, the swelling was measuring $2 \times 3 \mathrm{cms}$ in the region of earlier maxillectomy (Fig. 5A). CT scan was performed for the same, and it revealed a soft tissue density present heterogeneously in the region of left pterygopalatine fossa, extending superiorly and medially into the maxillary sinus and there was loss of fat plane with lateral pterygoid muscle. With 3D imaging, erosion of floor of the left orbit, left medial and lateral pterygoid plates were evident, suggesting a residual lesion (Fig. 5B).

Elaborate hematological investigations with electrolyte levels were done which revealed an increase in lymphocyte, ESR rate and hemoglobin level. The duration of the lesion with clinical behavior suggested possibilities of giant cell reparative granuloma, chronic fungal or bacterial infections, fibrosarcoma and osteosarcoma.

Treatment rendered was immediate resection to prevent the encroachment of the mass. The resected soft tissue mass was irregular in shape, grayish white in colour, measuring $4 \times 3 \mathrm{cms}$ with white solid areas seen on the cut surface. Histopathology revealed storiform pattern of arrangement of fibroblasts interspersed with atypical spindle cell to round to oval cells (Fig. 5C). Faint eosinophillic areas representing tumour osteoid was seen within the tumour mass. Osteoclasts like giant cells were seen in close association to tumour osteoid (Fig. 5D). Few areas suggested histiocytic type cells admixed with atypical fibroblasts and mitotic figures were also seen (Fig. 5E). The entire lesion varied in histological appearance from area to area. An immunohistochemical study was also carried out with CD68 to know the nature of histiocytes, but its focal positivity ruled out the malignant fibrous histiocytoma variant (Fig. 5F). Proliferating fibroblasts along with the typical tumour osteoid was more favoring a sarcomatous lesion like OS. A final diagnosis of fibroblastic variant of OS was given. Alveolar bone graft with osseointegrated implants has been considered on this patient at a later date.

\section{DISCUSSION}

OS are primarily bone producing malignant tumours arising most frequently in the long bones. Jaw OS usually occur one to two decades later than that of OS of other regions. Patients with OS usually have nonspecific clinical symptoms, the most common of which is pain associated with the swelling presenting from weeks or months. It has a bimodal age distribution, with a major peak in the second decade and a somewhat smaller peak after the age of 50. However, bimodal distribution of jaw lesions differ from those in the apppendicular skeleton, with the first peak occurring somewhat later, in the third decade [10]. The present case, with a critical clinical appearance of pain and swelling, is in accordance with the literature related to jaw OS, where patient presents with clinical symptoms in $3^{\text {rd }}$ and $4^{\text {th }}$ decade of life. These neoplasms often show typical behavior in the initial 


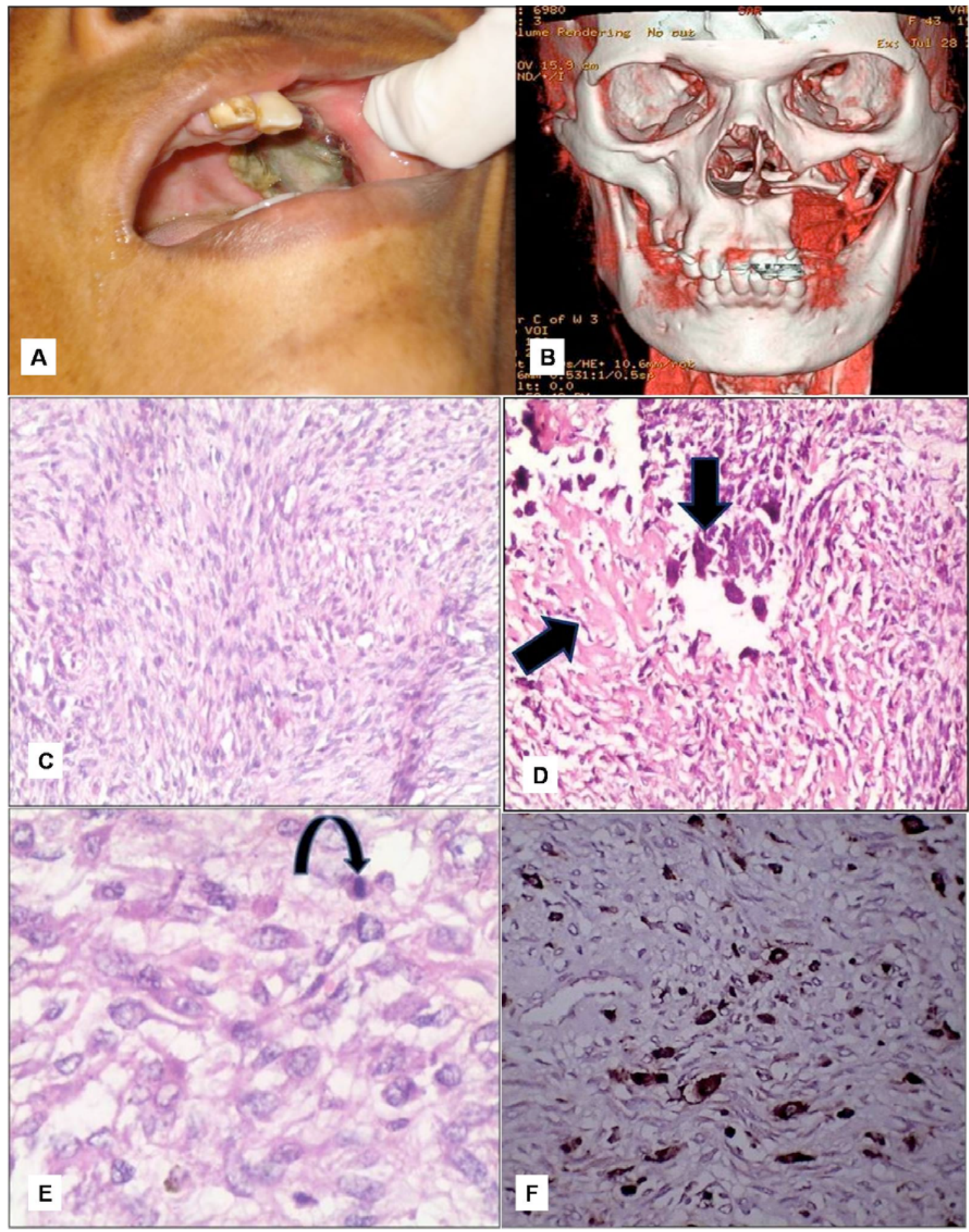

Fig. (5). A. Recurrent lesion measuring $2 \times 3 \mathrm{cms}$ in the maxillectomy region. B. 3D-imaging showing erosion of the floor of the left orbit. C. Storiform pattern of arrangement of fibroblasts with atypical; spindle cells. D. Osteoclasts like giant cells closely associated with tumour osteoid. E. Histiocytic type of cells admixed with atypical fibroblasts and atypical mitotic figures. F. Immunohistochemical CD68 marker study showing focal positivity for histiocytes.

phase presenting as a nondescript swelling, only to become overly aggressive in the later phase of the disease [11]. This was seen in our case as well, where the initial swelling was an unremarkable swelling leading to a preliminary diagnosis of periapical pathology. However, the swelling became significantly aggressive within a short span of time which led to emergency management of the lesion.
Histologically, although OS of jaws are almost similar to that of long bones, they are always better differentiated than the latter [12]. It has been reported that production of osteoid by malignant cells, even in small amounts, is diagnostic of OS $[13,14]$. Depending on the relative amounts of osteoid, cartilage, or collagen fibres present in the extracellular matrix, OS are categorized histopathologically into 
osteoblastic, chondroblastic, or fibroblastic subtypes [6]. In reality, most OS exhibit varying amounts of these three cell types and matrix [1]. Therefore, division into any one of these types is arbitrary and is generally meant to signify greater than $50 \%$ prevalence of any of these histologic types [1]. OS are known to vary in histologic pattern within same case with areas showing storiform pattern of fibrosarcoma to atypical elongated histiocytic like cells representing histiocytic tumours. Storiform pattern of fibroblasts with proliferating fibroblasts along with bundles of collagen fibers led to the diagnosis of fibrosarcoma in the initial biopsy in the present case. Further, there was a predominance of spindle cell proliferation in sweeping fascicles along with infrequent mitosis, occasional atypia and with focal areas showing giant cells, which again favored a diagnosis of fibrosarcoma.

Immunohistochemistry forms an integral part of pathologic diagnosis that aids in arriving at an accurate histopathological diagnosis. Vimentin, S-100 and CD68 markers were used to help in reaching the diagnosis. Vimentin was constantly positive with S-100 showing negativity, thus ruling out the possibility of neural tumours. Focal positivity with CD68 added on to the fibrohistiocytic nature of the tumours as quoted in the literature, to be one of the variants of OS [15]. Such challenging cases often pose a problem in executing a definitive surgical treatment option.

Radiographic evaluation is important in diagnosing OS as clinical symptoms like pain, swelling, paresthesia, and loosening of teeth are not specific [16]. Better knowledge of the radiological features can lead to an earlier diagnosis thus improving its prognosis [17]. Characteristic radiographic features include destruction of the cortical plates, widening of periodontal ligament space and perpendicular spiculated pattern of new periosteal bone formation [18]. However, these characteristic features are often missing and thus, OS is difficult to interpret as a result of varied appearance ranging from purely osteolytic or osteoblastic lesion, to a mixture of both [10]. The recurrent nature of the lesion with its aggressive nature, in our case, was confirmed by CT scan, where extensions into the orbit promoted a thorough sampling of the lesion. The classic appearance of tumour osteoid was the characteristic finding that led to the diagnosis of OS. Radiographs suggested a lytic destructive lesion while CT findings ruled out any metastasis.

The recurrence rate in large, bulky tumours is $80 \%$ within 24 months. Early diagnosis and radical surgery are the key factors for the better survival rate in this condition. Treatment of this lesion is radical surgery consisting of complete resection along with a margin of normal surrounding tissue, usually accompanied by chemotherapy. The best survival rate of five years was noted with radical surgery [12]. Anatomic limitations in face can cause some difficulties in achievement of uninvolved margins [19]. The combination of closed margins and poor histologic response appears to be the reason for high local recurrence of these lesions. The prognosis for patients after local recurrence of OS is poor.

Recent studies have focused on new markers for early detection of OS. Park et al. in their recent study showed by immunohistochemistry that high-grade OS of the jaws had a higher expression rate of proteins involved in regulation of growth and metastasis of cancer cells (ezrin and Metastatic tumour antigen) suggesting that their positivity can be used as additional prognostic markers in OS of the jaw [20]. Another study analyzed the clinicopathological features and immunohistochemical expression of p53, MDM2, CDK4, PCNA and Ki67 proteins in 25 head and neck OS and found $52 \%$ positivity for $\mathrm{p} 53,24 \%$ for MDM2, $84 \%$ for CDK4, 92\% for PCNA and $88 \%$ for Ki-67 suggesting PCNA as one of most favourable prognostic marker [21] . Another study suggested the role of 12q13-15 genes in OS of the jaws with amplification and overexpression of these genes might help in detecting high-grade tumours [22].

Response to chemotherapy (CT) is best seen in fibroblastic subtypes and poorest in chondroblastic subtype [11]. Multimodality therapy using chemotherapy and radiation treatment (RT) has shown improvement in survival rates in the OS of the extremity, from $20 \%$ to $70 \%$, which is better than the $40 \%$ survival rate reported for jaw OS [23]. A recent study which was performed to evaluate the outcomes of multimodality treatment in patients with OS of the jaw/craniofacial region with positive/uncertain resection margins, found that combined modality treatment, comprising of surgery and RT (median dose, 60 Gray) significantly improved local control $(\mathrm{P}=0.006)$ and overall survival $(\mathrm{P}<.0001)$ as compared to surgery alone [24]. In the case presented here, patient was subjected to partial maxillectomy coupled with RT \& CT and one episode of recurrence of tumour was reported at the time of write up, at a follow up for past one year. Multidimensional approaches including conventional surgical and prosthetic procedures, however, should be considered in accordance with the individual patient and specific defect.

Various new treatment modalities are being investigated for the treatment of OS of the jaws. A recent study focused on the expression of inducible nitric oxide synthase (iNOS) in OS of the jaw, and its relationship with tumour angiogenesis and clinicopathological characteristics. They concluded that iNOS may promote tumour angiogenesis in OS of the jaw and may present an important target in antitumour therapy [2]. Development of microvascular tissue transfer now offers various reconstructive options and has greatly improved the result of mid-face reconstruction [25].

\section{REFERENCES}

[1] Klein MJ, Siegal GP. Osteosarcoma: anatomic and histologic variants. Am J Clin Pathol 2006; 125: 555-81.

[2] Chen WL, Feng HJ, Li JS, Li HG. Expression and pathological relevance of inducible nitric oxide synthase in osteosarcoma of the jaws. Int J Oral Maxillofac Surg 2007; 36: 541-4.

[3] Amaral MB, Buchholz I, Freire-Maia B, et al. Advanced osteosarcoma of the maxilla: a case report. Med Oral Patol Oral Cir Bucal 2008; 13: E492-5.

[4] Garrington GE, Scofield HH, Cornyn J, Hooker SP. Osteosarcoma of the jaws. Analysis of 56 cases. Cancer 1967; 20: 377-91.

[5] Regezi JA, Zarbo RJ, McClatchey KD, Courtney RM, Crissman JD. Osteosarcomas and chondrosarcomas of the jaws: immunohistochemical correlations. Oral Surg Oral Med Oral Pathol 1987; 64: 302-7.

[6] Neville BW, Damm DD, Allen CM, Bouquot JE. Oral and Maxillofac Pathol. $2^{\text {nd }}$ ed. Philadelphia: WB Saunders; 2002.

[7] Friend SH, Bernards R, Rogelj S, et al. A human DNA segment with properties of the gene that predisposes to retinoblastoma and osteosarcoma. Nature 1986; 323: 643-6.

[8] Iavarone A, Matthay KK, Steinkirchner TM, Israel MA. Germ-line and somatic p53 gene mutations in multifocal osteogenic sarcoma. Proc Natl Acad Sci USA 1992; 89: 4207-9. 
[9] Hansen MF. Genetic and molecular aspects of osteosarcoma. J Musculoskelet Neuronal Interact 2002; 2: 554-60.

[10] Bennett JH, Thomas G, Evans AW, Speight PM. Osteosarcoma of the jaws: a 30-year retrospective review. Oral Surg Oral Med Oral Pathol Oral Radiol Endod 2000; 90: 323-32.

[11] Hayden JB, Hoang BH. Osteosarcoma: basic science and clinical implications. Orthop Clin North Am 2006; 37: 1-7.

[12] Clark JL, Unni KK, Dahlin DC, Devine KD. Osteosarcoma of the jaw. Cancer 1983; 51: 2311-6.

[13] Schajowicz F. Histological typing of tumours of bone; WHO international histological typing of tumours. Berlin: SpringerVerlag 1993.

[14] Dixit AG, Parikh NJ. Osteosarcoma of jaw bone. J Indian Acad Oral Med Radiol 2008; 20: 41-44.

[15] Del Vecchio A, Della Rocca C, Agrestini C, Criscuolo F, Manicone AM. [Histological and immunohistochemical studies in cases of malignant mesenchymal neoplasms of the oromaxillofacial area]. Minerva Stomatol 1994; 43: 199-206.

[16] Forteza G, Colmenero B, Lopez-Barea F. Osteogenic sarcoma of the maxilla and mandible. Oral Surg Oral Med Oral Pathol 1986; 62: $179-84$

[17] Givol N, Buchner A, Taicher S, Kaffe I. Radiological features of osteogenic sarcoma of the jaws. A comparative study of different radiographic modalities. Dentomaxillofac Radiol 1998; 27: 313-20.
[18] Petrikowski CG, Pharoah MJ, Lee L, Grace MG. Radiographic differentiation of osteogenic sarcoma, osteomyelitis, and fibrous dysplasia of the jaws. Oral Surg Oral Med Oral Pathol Oral Radiol Endod 1995; 80: 744-50.

[19] Bertoni F, Dallera P, Bacchini P, Marchetti C, Campobassi A. The istituto rizzoli-beretta experience with osteosarcoma of the jaw. Cancer 1991; 68: 1555-63.

[20] Park HR, Cabrini RL, Araujo ES, Paparella ML, Brandizzi D, Park YK. Expression of ezrin and metastatic tumor antigen in osteosarcomas of the jaw. Tumori 2009; 95: 81-6.

[21] Junior AT, de Abreu Alves F, Pinto CA, Carvalho AL, Kowalski LP, Lopes MA. Clinicopathological and immunohistochemical analysis of twenty-five head and neck osteosarcomas. Oral Oncol 2003; 39: 521-30.

[22] Lopes MA, Nikitakis NG, Ord RA, Sauk J, Jr. Amplification and protein expression of chromosome 12q13-15 genes in osteosarcomas of the jaws. Oral Oncol 2001; 37: 566-71.

[23] Carlson ER, Panella T, Holmes JD. Sarcoma of mandible. J Oral Maxillofac Surg 2004; 62: 81-7.

[24] Guadagnolo BA, Zagars GK, Raymond AK, Benjamin RS, Sturgis EM. Osteosarcoma of the jaw/craniofacial region: outcomes after multimodality treatment. Cancer 2009; 115: 3262-70.

[25] Futran ND, Mendez E. Developments in reconstruction of midface and maxilla. Lancet Oncol 2006; 7: 249-58.

Received: May 25, 2010

(C) Desai et al.; Licensee Bentham Open.

This is an open access article licensed under the terms of the Creative Commons Attribution Non-Commercial License (http://creativecommons.org/licenses/by-nc/3.0/) which permits unrestricted, non-commercial use, distribution and reproduction in any medium, provided the work is properly cited. 